\title{
Clinical features of COVID-19 in cancer patients within Wuhan, China
}

\author{
Li-Li Zhan ${ }^{1 \#}$, Yang Liu ${ }^{2 \#}$, Bi-Cheng Zhang ${ }^{4}$, Zhi-Min Deng ${ }^{1}$, Li Zhang ${ }^{5}$, Hua Liu ${ }^{1}$ Jing Yang ${ }^{3 *}$, \\ Yan-Xiang Cheng ${ }^{1 *}$
}

${ }^{1}$ Department of Gynaecology and Obstetrics, Renmin Hospital of Wuhan University, Wuhan, China; ${ }^{2}$ Department of Orthopedics, Renmin Hospital of Wuhan University, Wuhan, China; ${ }^{3}$ Reproductive Center, Renmin Hospital of Wuhan University, Wuhan, China; ${ }^{4}$ Department of Oncology, Renmin Hospital of Wuhan University, Wuhan, China; ${ }^{5}$ Department of Anesthesiology, Renmin Hospital of Wuhan University, Wuhan, China Contributions: (I) Conception and design: LL Zhan, Y Liu; (II) Administrative support: J Yang, YX Cheng; (III) Provision of study materials or patients: BC Zhang, ZM Deng; (IV) Collection and assembly of data: L Zhang, H Liu; (V) Data analysis and interpretation: All authors; (VI) Manuscript writing: All authors; (VII) Final approval of manuscript: All authors.

\#These authors contributed equally to this work.

*These authors contributed equally to this work.

Correspondence to: Prof. Yan-Xiang Cheng. Department of Gynaecology and Obstetrics, Renmin Hospital of Wuhan University, No. 99 Jiefang Road 238, Hubei Zhang Road (formerly Ziyang Road) Wuchang District, Wuhan 430060, China. Email: chengyanxiang1234@163.com; Prof. Jing Yang. Reproductive Center, Renmin Hospital of Wuhan University, No. 99 Jiefang Road 238, Hubei Zhang Road (formerly Ziyang Road) Wuchang District, Wuhan 430060, China. Email: dryangjing@whu.edu.cn

Background: There have been few reports on cancer patients with COVID-19 since its outbreak. Our study aimed to understand the clinical features of cancer patients with COVID-19 and determine the impact of surgery and chemotherapy on the patients' conditions.

Methods: Seventy COVID-19 patients from Renmin Hospital of Wuhan University, including 18 cancer patients, were enrolled in this study. Patients were classified into moderate or severe cases of COVID-19 and as well as non-cancer or cancer patients. Cancer patients were further grouped into Group A (prevalent cases with cancer history) and Group B (incident cases who underwent cancer treatment recently). Laboratory results were analyzed to determine whether cancer-related surgery and chemotherapy worsened the condition of cancer patients. The patients presented with clinical symptoms of COVID-19, including fever, dry cough, and polypnea; blood tests also revealed decreased lymphocyte counts and cellular immune function, and examination of CT scans revealed patchy ground-glass opacity of lungs.

Results: The results showed a significant difference $(\mathrm{P}<0.05)$ in levels of CD3 CD4 T lymphocytes and D-dimer between non-cancer and cancer patients with moderate COVID-19; there was also a significant difference $(\mathrm{P}<0.05)$ in levels of $\mathrm{D}$-dimer between non-cancer and cancer patients with severe COVID-19. Except for liver function, there was no significant difference $(\mathrm{P}>0.05)$ between cancer patients in Group A and $\mathrm{B}$ with moderate COVID-19. A significant difference $(\mathrm{P}<0.05)$ in neutrophil-to-lymphocyte ratio (NLR) and CD4 T lymphocytes was observed between cancer patients with moderate COVID-19 and those with severe COVID-19.

Conclusions: The results indicated that chemotherapy and surgery might not worsen the conditions of COVID-19 patients. NLR and CD4 T lymphocyte might be used as effective indicators for the conditions of cancer patients with COVID-19.

Keywords: COVID-19; novel coronavirus pneumonia; cancer; neutrophil-to-lymphocyte ratio (NLR); CD4 T lymphocyte

Submitted May 31, 2021. Accepted for publication Jul 13, 2021.

doi: 10.21037/apm-21-1596

View this article at: https://dx.doi.org/10.21037/apm-21-1596 


\section{Introduction}

At the end of December 2019, Wuhan, a city located in Hubei province of China, experienced an outbreak of a novel coronavirus that causes respiratory illness. The virus spread rapidly throughout China by person-toperson transmission, resulting in severe consequences such as damage to the alveolar, progressive respiratory failure, and even death (1-4). This virus was later named severe acute respiratory syndrome coronavirus 2 (SARSCov-2) and the disease caused by SARS-Cov-2 was named coronavirus disease 2019 (COVID-19) by the World Health Organization (WHO) (5).

In general, cancer patients are immunosuppressive, which is a distinct characteristic of cancer patients comparing patients with other comorbidities, such as hypertension or diabetes (6). Whether such an immunosuppressive state could lead to worse conditions of COVID-19 is not clear. So far, there is limited evidence on the clinical presentation of COVID-19 in cancer patients, and whether cancerrelated therapies, i.e., chemotherapy and surgery, could affect the outcomes and progression of the disease is unknown. With the widespread of COVID-19, more and more cancer patients are to be infected with this virus, and understanding the clinical characteristics of cancer patients with COVID-19 may help to improve the targeted treatments and enhance recovery. In this study, we aimed to focus on cancer patients with COVID-19, analyzing the clinical characteristics of these patients, and investigating any potential effect of anti-cancer treatment, i.e., surgery or chemotherapy, on the clinical progression of COVID-19. We present the following article in accordance with the STROBE reporting checklist (available at https://dx.doi. org/10.21037/apm-21-1596).

\section{Methods}

\section{Study design and participants}

Seventy COVID-19 patients from Renmin Hospital of Wuhan University were included between January 31, 2020, and February 26, 2020, including 18 patients with diagnosed malignancy. The diagnosis of COVID-19 was based on (I) the positiveness of the novel coronavirus nucleic acid in respiratory tract samples using RT-PCR, and (II) patchy ground-glass opacity in the computed tomography (CT) of the lungs. All participants were treated according to the "Diagnosis and Treatment Remedy of COVID-19 (Trial Edition 6th)" (7) issued by the National Health Commission of China. All participants were cured and discharged alive from the hospital. All procedures performed in this study involving human participants were in accordance with the Declaration of Helsinki (as revised in 2013). This study was reviewed and approved by the Medical Ethical Committee of Renmin Hospital of Wuhan University (approval number WDRY2020-K087), and informed consent was taken from all the patients.

All participants were classified into moderate or severe groups depending on the severity of COVID-19. The cancer patients were further classified into cancer group A (prevalent cases with cancer history) and cancer group B (incident cases who underwent cancer treatment recently). Prevalent cancer patients were defined as those with more than 1 year of cancer history and did not receive cancerrelated treatment within one month before the diagnosis of COVID-19, while incident cancer patients were defined as those who received cancer-related treatment, i.e., surgery or chemotherapy, within one month before the diagnosis of COVID-19. The age and gender distributions were balanced among these groups.

\section{Indicators of observation}

Clinical, Biochemical indicators including levels of white blood cell count, neutrophil, lymphocyte count, the neutrophil-to-lymphocyte ratio (NLR), red blood cell count, hemoglobin, CD4 T cell count, CD8 T cell count, CD4/CD8 ratio, and D-dimers were compared between the moderate and severe groups as well as patients with and without cancer.

\section{Statistical analysis}

All analyses were processed by SSPS 25 software. Data were expressed by mean \pm standard deviation if they were normally distributed or by median (quartiles) if they were not. Nonparametric rank-sum test, chi-square test, ANOVA, and $t$-test were performed according to the data type.

\section{Results}

\section{Clinical features of COVID-19 in cancer patients}

The clinical characteristics of the 18 cancer patients included in this study were presented in Table 1 . The average age was 60.7 years old (range 44-77). The most 
Table 1 Cancer patients with novel coronavirus pneumonia

\begin{tabular}{|c|c|c|c|}
\hline Variable & Total $(\mathrm{N}=18), \mathrm{n}(\%)$ & Group A (N=10), n (\%) & Group B (N=8), n (\%) \\
\hline Male & $9(50.0)$ & $7(70.0)$ & 2 \\
\hline Female & $9(50.0)$ & $3(30.0)$ & 6 \\
\hline Age (years), mean \pm SD & $60.6 \pm 11.1$ & $61.9 \pm 11.6$ & $59.0 \pm 11.1$ \\
\hline Rectal cancer & 5 & 3 & 3 \\
\hline Cervical cancer & 3 & 1 & 2 \\
\hline Bladder cancer & 2 & 2 & 0 \\
\hline Lung cancer & 2 & 1 & 1 \\
\hline Breast cancer & 1 & 1 & 0 \\
\hline Nasopharyngeal carcinoma & 1 & 0 & 1 \\
\hline Recurrent leiomyosarcoma & 1 & 0 & 1 \\
\hline \multicolumn{4}{|l|}{ Underlying disease } \\
\hline Hypertension & 6 & 4 & 2 \\
\hline Diabetes & 7 & 3 & 4 \\
\hline Coronary disease & 1 & 1 & 0 \\
\hline No & 4 & 2 & 2 \\
\hline Pulmonary infection & 5 & 0 & 5 \\
\hline Pulmonary nodule & 2 & 1 & 1 \\
\hline Normal & 11 & 9 & 2 \\
\hline \multicolumn{4}{|l|}{ Recent treatments } \\
\hline Surgery & 5 & 0 & 5 \\
\hline Chemotherapy & 3 & 0 & 3 \\
\hline \multicolumn{4}{|l|}{ Signs } \\
\hline Fever & 17 & 10 & 7 \\
\hline Chest tightness & 8 & 5 & 3 \\
\hline Fatigue & 4 & 2 & 2 \\
\hline Dry cough & 6 & 3 & 3 \\
\hline Polypnea & 6 & 2 & 4 \\
\hline
\end{tabular}

Table 1 (continued) 
Table 1 (continued)

\begin{tabular}{|c|c|c|c|}
\hline Variable & Total $(\mathrm{N}=18), \mathrm{n}(\%)$ & Group A (N=10), n (\%) & Group B $(\mathrm{N}=8), \mathrm{n}(\%)$ \\
\hline Expectoration & 2 & 1 & 1 \\
\hline Diarrhea & 1 & 0 & 1 \\
\hline \multicolumn{4}{|l|}{ Laboratory finding } \\
\hline Decreased Lymphocyte count & 9 & 6 & 3 \\
\hline Patchy ground-glass opacity of lungs & 18 & 10 & 7 \\
\hline
\end{tabular}

$\mathrm{SD}$, standard deviation.
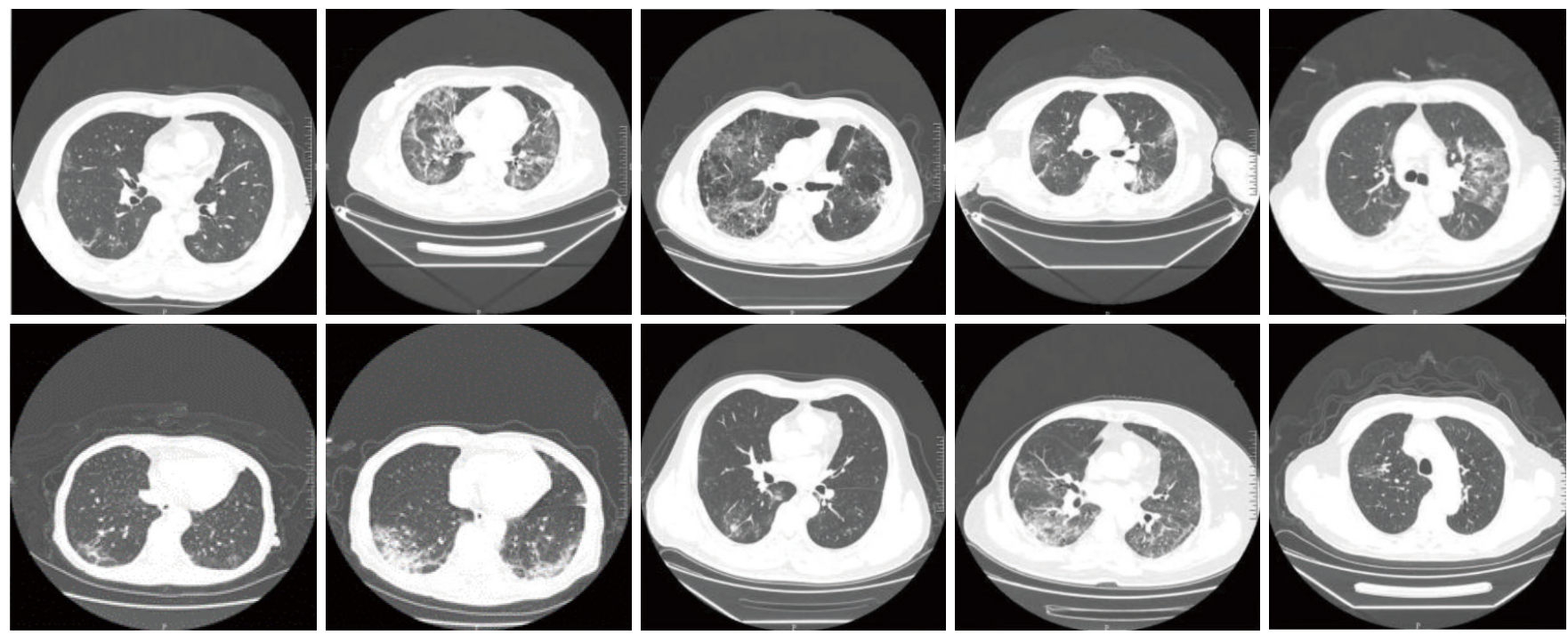

Figure 1 Chest CT scans from cancer patients group A with coronavirus disease 2019 (COVID-19).

common symptom of COVID-19 among these patients was fever (94\%), followed by chest tightness (44\%), dry cough (33\%), and polypnea (33\%). Chest CT scans revealed patchy ground-glass opacity in the lungs (Figures 1,2). The most common cancer type was rectal cancer $(61 \%)$. White blood cell counts were increased in 2 patients and decreased in 4 patients. Lymphocyte counts were decreased in 9 patients, and cellular immune function, i.e., counts of CD4 and CD8 T lymphocytes, showed some extent of reduction in 10 patients. D-dimer levels were higher than normal in the cancer patients.

Additionally, 1 patient showed abnormal renal function, and 5 patients showed impairment in liver functions.

The moderate group included 44 patients, among whom
14 were cancer patients. The severe group included 26 patients, among whom 4 were cancer patients. Cancer group A consisted of 10 patients, among whom 7 were in the moderate group, and 3 were in the severe group. Cancer group B consisted of 8 patients, among whom 7 were in the moderate group and 1 was in the severe group. There was no difference in the distributions of age, gender, or underlying diseases between these groups. None of the patients in group A had a history of pulmonary infection before the infection of COVID-19. However, in group B, 5 patients had a previous pulmonary infection. There were 4 cases of mild liver dysfunction in group A and 1 case in group B, all of whom were moderate cases and had other comorbidities. 

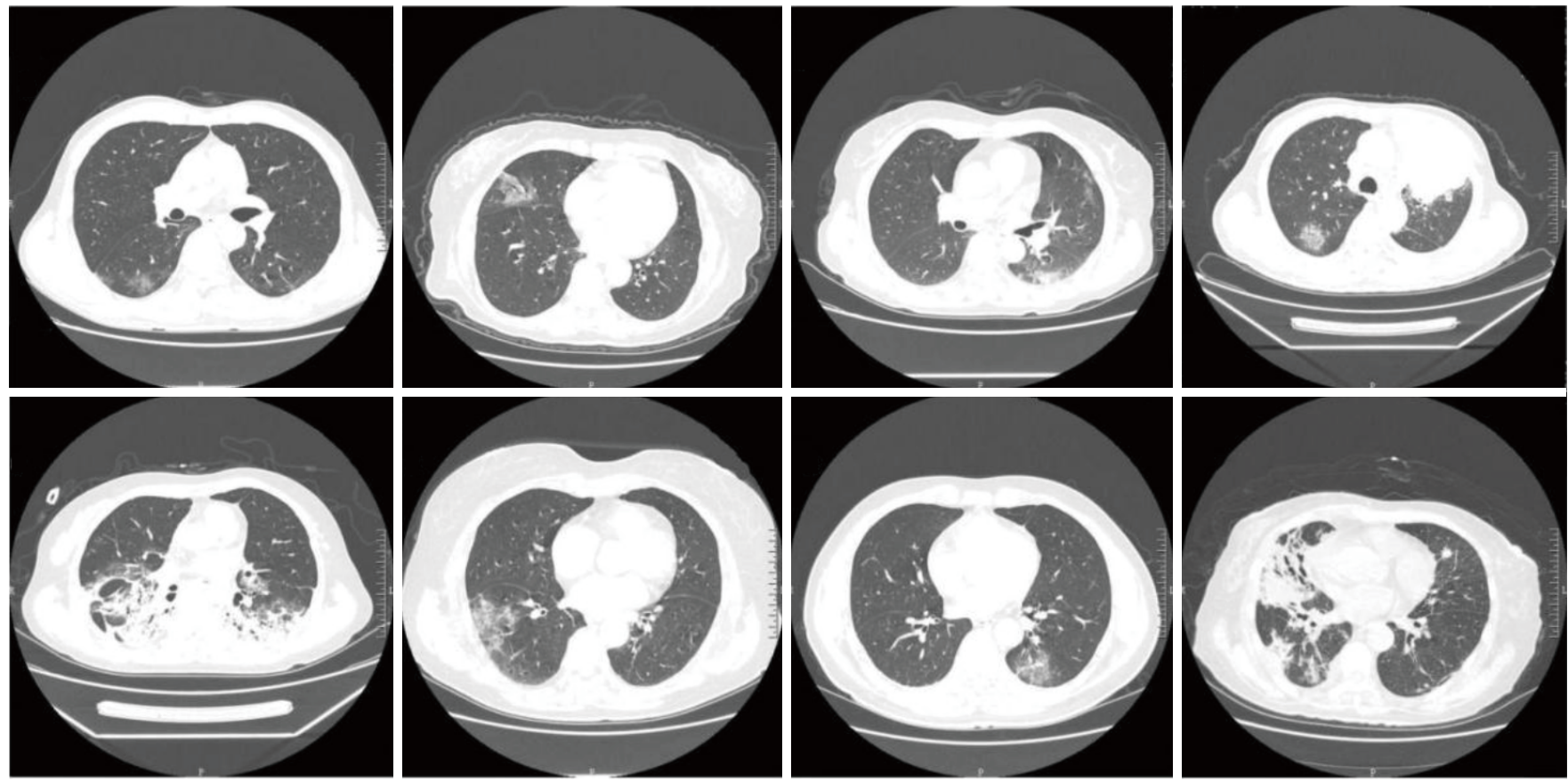

Figure 2 Chest CT scans from cancer patients group B with coronavirus disease 2019 (COVID-19).

\section{Effective indicators for monitoring changes in the conditions of cancer patients with COVID-19}

Clinical laboratory tests of cancer patients (Figure 3) revealed that the NLR was higher, and the CD4 T lymphocytes count was lower in cancer patients with severe COVID-19 compared with those with moderate COVID-19 (for NLR P=0.019, for CD4 T lymphocytes $\mathrm{P}=0.044$ ). Besides, a statistically significant difference in liver function was observed between the two groups. However, such difference might not be related to COVID-19. Therefore, NLR values and CD4 T lymphocyte levels were used to monitor the conditions of the cancer patients.

\section{The differences between cancer and non-cancer patients with moderate and severe COVID-19}

Among patients with moderate COVID-19, significant differences were found in the levels of CD3 T lymphocytes, CD4 $\mathrm{T}$ lymphocytes, and D-dimer comparing patients with and without cancer (Figure 4). Meanwhile, among patients with severe COVID-19, the $\mathrm{D}$-dimer level $(\mathrm{P}=0.007)$ was higher in cancer patients compared with that in non-cancer patients. The NLR values were similar between cancer patients and non-cancer patients regardless of the severity of COVID-19 (Figure 4).

\section{The effect of chemotherapy and surgery on the cancer patients with moderate COVID-19}

To investigate whether chemotherapy or surgery might worsen the conditions of cancer patients, the clinical data from cancer group A and group B among patients with moderate COVID-19 were compared. The results showed no significant difference $(\mathrm{P}>0.05)$ in all indicators except for liver functions (Figure 5).

\section{Discussion}

By February $26^{\text {th }}, 2020$, a total of 78,191 people had been diagnosed with COVID-19 in China. The most common clinical manifestations of COVID-19 are fever, fatigue, dry cough, and polypnea (8). The virus spreads through the mucosa of the respiratory tract and infects other cells, inducing a series of immune responses and causing changes in immune cells such as peripheral leukocytes and lymphocytes (9).

To date, there are few studies on the clinical features of cancer patients with COVID-19. Cancer patients are usually under immunosuppressive conditions, of which the 

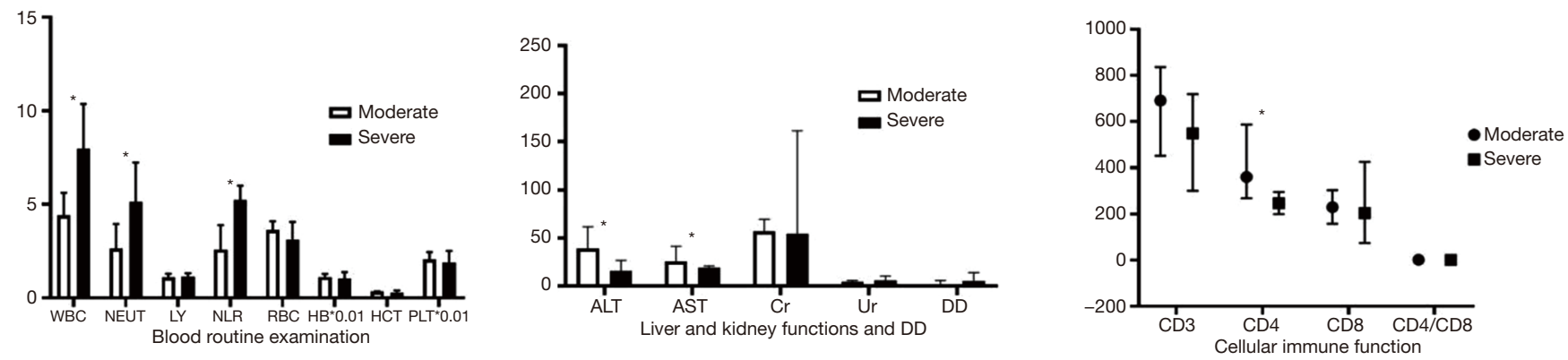

Figure 3 Compare of clinical data of cancer patients in moderate and severe type. * $0.01<\mathrm{P}<0.05$; without any mark, $\mathrm{P}>0.05$. WBC, white blood cell count $\left(\times 10^{9} / \mathrm{L}\right)$; NEUT, neutrophil count $\left(\times 10^{9} / \mathrm{L}\right)$; LY, lymphocyte count $\left(\times 10^{9} / \mathrm{L}\right)$; NLR, neutrophil-to-lymphocyte ratio; RBC, red blood cell count $\left(\times 10^{12} / \mathrm{L}\right)$; HB $\times 0.01$, hemoglobin $(\mathrm{g} / \mathrm{L}) \times 0.01 ; \mathrm{HCT}$, hemoglobin $(\mathrm{L} / \mathrm{L}) ; \mathrm{PLT} \times 0.01$, platelet count $\left(\times 10^{9} / \mathrm{L}\right) \times 0.01$; ALT, alanine aminotransferase (U/L); AST, aspartate aminotransferase (U/L); Cr, creatinine ( $\mu \mathrm{mol} / \mathrm{L})$; Ur, blood urea nitrogen $(\mathrm{mmol} / \mathrm{L})$; CD3, CD3 T lymphocytes (per/ $\mu \mathrm{L})$; CD4, CD4 T lymphocytes (per/ $\mu \mathrm{L})$; CD8, CD8 T lymphocytes (per/ $\mu \mathrm{L})$; CD4/CD8, CD4-to-CD8 ratio.

In moderate type

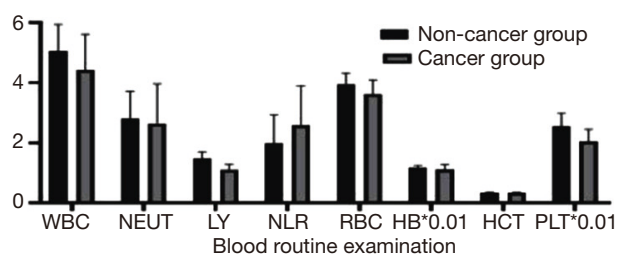

In severe type

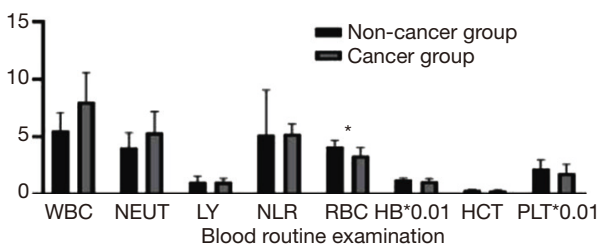

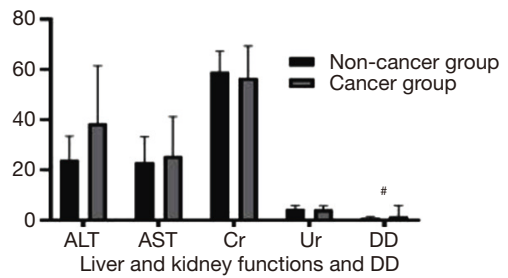
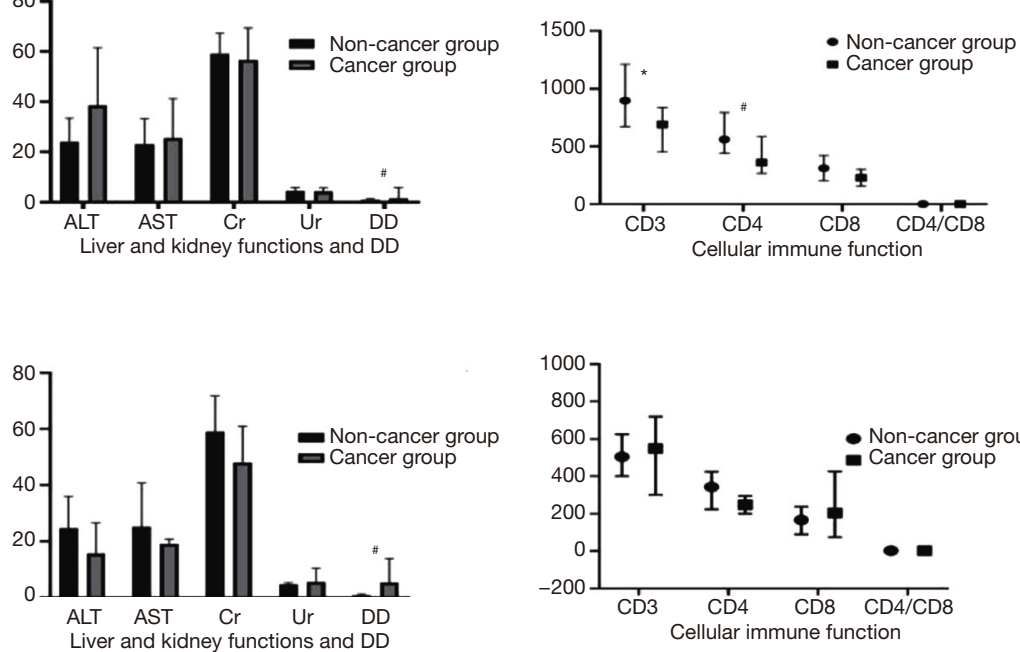

Figure 4 Compare of cancer and non-cancer patients in moderate and severe type. ${ }^{*}, 0.01<\mathrm{P}<0.05$;, $\mathrm{P}<0.01$; without any mark, $\mathrm{P}>0.05$. WBC, white blood cell count $\left(\times 10^{9} / \mathrm{L}\right)$; NEUT, neutrophil count $\left(\times 10^{9} / \mathrm{L}\right)$; LY, lymphocyte count $\left(\times 10^{9} / \mathrm{L}\right)$; NLR, neutrophil-to-lymphocyte ratio; RBC, red blood cell count $\left(\times 10^{12} / \mathrm{L}\right)$; HB $\times 0.01$, hemoglobin $(\mathrm{g} / \mathrm{L}) \times 0.01 ; \mathrm{HCT}$, hemoglobin $(\mathrm{L} / \mathrm{L})$; PLT $\times 0.01$, platelet count $\left(\times 10^{9} / \mathrm{L}\right) \times 0.01$; ALT, alanine aminotransferase (U/L); AST, aspartate aminotransferase $(\mathrm{U} / \mathrm{L}) ; \mathrm{Cr}$, creatinine $(\mu \mathrm{mol} / \mathrm{L})$; Ur, blood urea nitrogen $(\mathrm{mmol} / \mathrm{L})$;

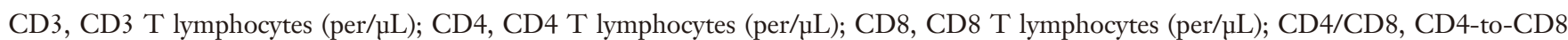
ratio.

immune responses are suppressed by the negative regulatory pathways, inhibition of the pro-inflammatory signals, and the maintained disease stability (10). Investigating the clinical features of cancer patients with COVID-19 is vital for the appropriate medical management of these patients. Eighteen cancer patients with COVID-19 were included in this study, of which 14 were moderate cases, and 4 were severe cases. These patients' symptoms, laboratory examination results, and chest CT images were consistent with that in COVID-19 patients of the general population.

The differences in laboratory results between cancer and non-cancer patients with COVID-19 were also investigated. The results showed that the cancer group had lower levels of CD3 and CD4 T lymphocytes, and higher levels of D-dimer than those of the non-cancer group. These findings may be attributed to the hypercoagulable and 
In moderate type
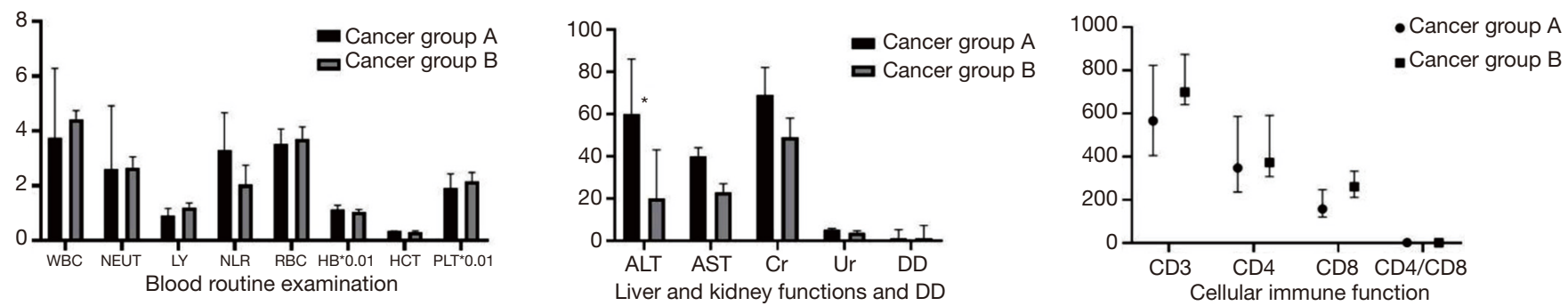

Figure 5 Compare of cancer group A and group B in moderate type. *, $0.01<\mathrm{P}<0.05$; without any mark, $\mathrm{P}>0.05$. WBC, white blood cell count $\left(\times 10^{9} / \mathrm{L}\right)$; NEUT, neutrophil count $\left(\times 10^{9} / \mathrm{L}\right)$; LY, lymphocyte count $\left(\times 10^{9} / \mathrm{L}\right)$; NLR, neutrophil-to-lymphocyte ratio; RBC, red blood cell count $\left(\times 10^{12} / \mathrm{L}\right)$; HB $\times 0.01$, hemoglobin $(\mathrm{g} / \mathrm{L}) \times 0.01$; HCT, hemoglobin $(\mathrm{L} / \mathrm{L})$; PLT $\times 0.01$, platelet count $\left(\times 10^{9} / \mathrm{L}\right) \times 0.01 ;$ ALT, alanine aminotransferase (U/L); AST, aspartate aminotransferase (U/L); Cr, creatinine ( $\mu \mathrm{mol} / \mathrm{L})$; Ur, blood urea nitrogen (mmol/L); CD3, CD3 T

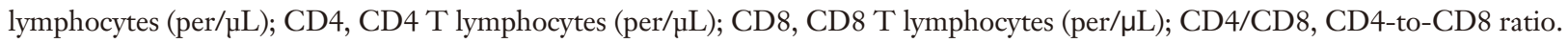

immunosuppressive state of cancer patients. Nevertheless, further research is warranted to fully understand the associations.

The diagnostic tests for COVID-19 are nucleic acid tests on nasopharyngeal swabs and CT scans of the lungs (7). It is important to rapidly predict the disease progression in order to provide suitable treatment. Studies have shown that COVID-19 infection can lead to a decrease in total lymphocytes and lymphocytes subset, which can be used to monitor the disease progression (11-13). Studies have also proposed NLR as an effective indicator for predicting disease progression (13-15). In a study (15) of 115 patients with COVID-19, NLR was identified as an independent risk factor for severe COVID-19. High levels of NLR may suggest a poor prognosis (13). Our research demonstrated that among cancer patients, the NLR and CD4 T lymphocytes in patients with moderate COVID-19 are different from those in patients with severe COVID-19. The severity of COVID-19 was positively correlated with NLR levels and negatively with CD4 T lymphocytes levels. Liver impairment was also indicated in cancer patients with COVID-19. Liver impairment was more severe in patients with moderate COVID-19 than in those with severe COVID-19; however, the clinical significance of this difference needs further interpretation. A study analyzing liver impairment in COVID-19 patients (15) showed that the impairment of liver function might not influence the clinical outcomes. Thus, NLR values and CD4 T lymphocyte levels, but not liver impairment, might be used to predict the COVID-19 progressions in cancer patients.

Surgery and chemotherapy are common treatments for cancer, which may deteriorate physical conditions and cause immune system dysfunction while treating against cancers. Tan et al. (16) confirmed that in cervical cancer patients, the suppressed immune effect of $\mathrm{T}$ lymphocytes was recovered after surgery and further strengthened after infection. Li et al. (17) investigated the effects of chemotherapy on the immune system and determined that chemotherapeutic drugs can selectively kill regulatory $\mathrm{T}$ cells and inhibit immune responses in patients with non-small cell lung cancer. Until now, no study has investigated the effect of cancer-related surgery or chemotherapy among patients of COVID-19.

The results of our study comparing the laboratory tests between cancer patients who recently were treated with surgery or chemotherapy and those did not show that except for the liver function, there was no statistical difference between these two groups of cancer patients with moderate COVID-19, indicating that cancer-related surgery and chemotherapy treatments may have limited effect on the conditions of COVID-19 patients.

A study published by Liang et al. (18) analyzed a total of 2,007 COVID-19 patients in 31 provinces and cities, collected before January $31^{\text {st }}, 2020$. Of these cases, 18 were cancer patients, accounting for $0.8 \%$ of the total number of patients. A study conducted by the Chinese Center for Disease Control and Prevention analyzed 44,672 confirmed cases of COVID-19 before February $11^{\text {th }}, 2020$, among which 107 were cancer patients $(0.2 \%)$. The case fatality rate of these cancer patients was lower than that of patients with other diseases (19). Although the rate of COVID-19 infection in cancer patients is low, prevention and treatment 
are still of vital importance.

With increasingly emerging evidence, the public health prevention and the clinical treatments of COVID-19 have been improved a lot since its outbreak in Wuhan. Different guidelines have been established by both the health agencies in individual countries as well as the WHO. Individual measures that have been promoted in most countries to reduce the spread of COVID-19 include hand hygiene, social distance, and personal protection equipment. The treatments for COVID-19 include isolation, symptomatic treatment, and oxygen support as proposed by the WHO guidelines (https://www.who.int/publications/i/item/ WHO-2019-nCoV-clinical-2021-1). However, most of these guidelines are not tailored for cancer patients, highlighting the need for further research.

In conclusion, chemotherapy and surgery may not worsen the conditions of COVID-19 patients. The susceptibility to COVID-19 may be due to the invasion of the novel coronavirus into the body by acting on the ACE2 receptor (20). CD4 T lymphocytes and NLR levels can serve as indicators of the physical conditions of cancer patients with COVID-19. The study was limited by its small sample size. Although data were collected from 70 patients, only 18 of them were cancer patients. As one of the novel studies to analyze the clinical features of COVID-19 in cancer patients, these results added knowledge to the existing literature and provided the base for subsequent studies on cancer patients with COVID-19.

\section{Acknowledgments}

I really give my thanks to my professors, my family and my friends. Without them, we could not finish this paper. Most of all, I give my great honor to my colleagues not only in Renmin Hospital of Wuhan University, for their selfless devotion in the battle with COVID-19.

Funding: None.

\section{Footnote}

Reporting Checklist: The authors have completed the STROBE reporting checklist. Available at https://dx.doi. org/10.21037/apm-21-1596

Data Sharing Statement: Available at https://dx.doi. org/10.21037/apm-21-1596

Conflicts of Interest: All authors have completed the ICMJE uniform disclosure form (available at https://dx.doi. org/10.21037/apm-21-1596). The authors have no conflicts of interest to declare.

Ethical Statement: The authors are accountable for all aspects of the work in ensuring that questions related to the accuracy or integrity of any part of the work are appropriately investigated and resolved. All procedures performed in this study involving human participants were in accordance with the Declaration of Helsinki (as revised in 2013). This study was reviewed and approved by the Medical Ethical Committee of Renmin Hospital of Wuhan University (approval number WDRY2020-K087), and informed consent was taken from all the patients.

Open Access Statement: This is an Open Access article distributed in accordance with the Creative Commons Attribution-NonCommercial-NoDerivs 4.0 International License (CC BY-NC-ND 4.0), which permits the noncommercial replication and distribution of the article with the strict proviso that no changes or edits are made and the original work is properly cited (including links to both the formal publication through the relevant DOI and the license). See: https://creativecommons.org/licenses/by-nc-nd/4.0/.

\section{References}

1. Wang C, Horby PW, Hayden FG, et al. A novel coronavirus outbreak of global health concern. Lancet 2020;395:470-3.

2. Huang C, Wang $\mathrm{Y}, \mathrm{Li}$ X, et al. Clinical features of patients infected with 2019 novel coronavirus in Wuhan, China. Lancet 2020;395:497-506.

3. Zhu N, Zhang D, Wang W, et al. A Novel Coronavirus from Patients with Pneumonia in China, 2019. N Engl J Med 2020;382:727-33.

4. Chan JF, Yuan S, Kok KH, et al. A familial cluster of pneumonia associated with the 2019 novel coronavirus indicating person-to-person transmission: a study of a family cluster. Lancet 2020;395:514-23.

5. Lai CC, Shih TP, Ko WC, et al. Severe acute respiratory syndrome coronavirus 2 (SARS-CoV-2) and coronavirus disease-2019 (COVID-19): The epidemic and the challenges. Int J Antimicrob Agents 2020;55:105924.

6. Chen DS, Mellman I. Elements of cancer immunity and the cancer-immune set point. Nature 2017;541:321-30.

7. National health commission, PRC. Diagnosis and treatment of new coronavirus pneumonia (trial 6th edition) 
(EB/OL) (2020-02-18). Available online: http://www.nhc. gov.cn/xcs/zhengcwj/202002/8334a8326dd94d329df351d7 da8aefc2.shtml

8. Wang D, Hu B, Hu C, et al. Clinical Characteristics of 138 Hospitalized Patients With 2019 Novel CoronavirusInfected Pneumonia in Wuhan, China. JAMA 2020;323:1061-9.

9. Chen N, Zhou M, Dong X, et al. Epidemiological and clinical characteristics of 99 cases of 2019 novel coronavirus pneumonia in Wuhan, China: a descriptive study. Lancet 2020;395:507-13.

10. Mellman I, Coukos G, Dranoff G. Cancer immunotherapy comes of age. Nature 2011;480:480-9.

11. Wang F, Nie J, Wang H, et al. Characteristics of Peripheral Lymphocyte Subset Alteration in COVID-19 Pneumonia. J Infect Dis 2020;221:1762-9.

12. Chen G, Wu D, Guo W, et al. Clinical and immunological features of severe and moderate coronavirus disease 2019. J Clin Invest 2020;130:2620-9.

13. Qin C, Zhou L, Hu Z, et al. Dysregulation of Immune Response in Patients With Coronavirus 2019 (COVID-19) in Wuhan, China. Clin Infect Dis 2020;71:762-8.

14. Lagunas-Rangel FA. Neutrophil-to-lymphocyte ratio and lymphocyte-to-C-reactive protein ratio in patients with severe coronavirus disease 2019 (COVID-19): A metaanalysis. J Med Virol 2020;92:1733-4.

Cite this article as: Zhan LL, Liu Y, Zhang BC, Deng ZM, Zhang L, Liu H, Yang J, Cheng YX. Clinical features of COVID-19 in cancer patients within Wuhan, China. Ann Palliat Med 2021;10(7):8094-8102. doi: 10.21037/apm-21-1596
15. Zhang Y, Zheng L, Liu L, et al. Liver impairment in COVID-19 patients: A retrospective analysis of 115 cases from a single centre in Wuhan city, China. Liver Int 2020;40:2095-103.

16. Tan XF, Xu HJ, Guo LH, et al. Changes of T lymphocyte immune function and its clinical meaning in patients with postoperative infection of cervical cancer. Chinese Journal of Nosocomiology 2015;6:1270-2.

17. Li JY, Duan XF, Wang LP, et al. Selective depletion of regulatory $T$ cell subsets by docetaxel treatment in patients with nonsmall cell lung cancer. J Immunol Res 2014;2014:286170.

18. Liang W, Guan W, Chen R, et al. Cancer patients in SARS-CoV-2 infection: a nationwide analysis in China. Lancet Oncol 2020;21:335-7.

19. Epidemiology of emergency response group for new coronavirus pneumonia at Chinese center for disease control and prevention. Analysis on epidemiological characteristics of new coronavirus pneumonia. Chinese Journal of Epidemiology 2020;41:145-51.

20. Yan R, Zhang Y, Li Y, et al. Structural basis for the recognition of SARS-CoV-2 by full-length human ACE2. Science 2020;367:1444-8.

(English Language Editors: G. Stone and J. Chapnick) 